\title{
Kongruensi Unsur Idempoten Ortogonal dalam Aljabar Insidensi Finitary
}

\author{
Ema Carnia $^{\left.1^{*}\right)}$, Sri Wahyuni ${ }^{2)}$, Irawati $^{3)}$, dan Setiadji ${ }^{2)}$ \\ 1) Jurusan Matematika, Fakultas Matematika dan IImu Pengetahuan Alam, Universitas Padjadjaran, \\ Jalan Raya Bandung-Sumedang Km.21 Jatinangor, Sumedang 45363 \\ 2) Jurusan Matematika, Fakultas Matematika dan Ilmu Pengetahuan Alam, Universitas Gadjah Mada, \\ Jalan Sekip Utara Bulak Sumur 21, Yogyakarta 55281 \\ 3)Jurusan Matematika, Fakultas Matematika Ilmu dan Pengetahuan Alam, Institut Teknologi Bandung, \\ Jalan Ganesha 10, Bandung 40132
}

Diterima 24-05-2010 Disetujui 04-09-2010

\begin{abstract}
Let $X$ be a partially ordered set, $R$ is a commutative ring with identity and FININC $(X, R)$ denote finitary incidence algebra of poset $X$ over $R$. In this paper it will be seen congruence of two elements that are idempotent orthogonal in FININC (X, R) relative to the modulo Radical Jacobson of algebra. Review of this topic would be useful to examine isomorphism problems of the finitary incidence Algebra.
\end{abstract}

Keywords : finitary incidence algebra, idempotent orthogonal, radical Jacobson

\section{PENDAHULUAN}

Munculnya tulisan ini termotivasi oleh penemuan Kripchenko dan Novikov, (2009), tentang aljabar insidensi finitary atas suatu struktur lapangan yang bekerja pada sembarang partially ordered set (poset). Hal ini merupakan penemuan baru yang cukup besar yang terkait dengan teori aljabar insidensi. Selama ini penelitian tentang aljabar insidensi selalu dibatasi pada poset tertentu, yaitu poset yang bersifat locally finite. Dalam tulisannya mereka membuat aljabar insidensi finitary dari himpunan semua deret finitary. Deret tersebut diperoleh dari himpunan formal sum yang sebelumnya telah didefinisikan oleh Stanley, (1970), dengan cara menambahkan syarat keterhinggaan. Hal ini dilakukan karena jika posetnya diperumum (tidak harus locally finite), maka himpunan semua formal sum bukan merupakan aljabar, namun hanya merupakan ruang insidensi saja. Setelah diberikan syarat tambahan maka diperoleh aljabar insidensi finitary pada sembarang poset atas suatu lapangan yang memiliki struktur aljabar asosiatif. Sedangkan ruang insidensinya mempunyai struktur modul atas aljabar insidensi finitary.

\footnotetext{
*Telp: +628122371388

Email: ema_carnia@yahoo.com
}

Dalam tulisan ini telah ditemukan pula syarat perlu dan cukup agar elemen dalam deret finitary bersifat invertibel, yang mengakibatkan munculnya syarat perlu dan cukup suatu elemen dalam aljabar insidensi finitary berada di radikal Jacobson aljabar tersebut.

Penemuan lain yang diperoleh adalah kaitan unsur idempoten dengan idempoten diagonal dalam aljabar insidensi finitary. Selain itu adanya kaitan antara elemen reguler dengan elemen idempoten diagonal dan elemen yang invertibel dalam aljabar insidensi finitary juga telah dibahas. Dalam tulisan ini sama sekali tidak membahas masalah isomorfisma.

Seperti telah diketahui bersama bahwa topik isomorfisma merupakan topik populer dalam bidang Matematika, khususnya aljabar karena memberikan kontribusi besar dan dapat diterapkan dalam berbagai struktur aljabar. Khusus untuk masalah isomorfisma pada aljabar insidensi telah diteliti sejak lama, antara lain oleh Stanley, (1970), yang bekerja atas lapangan dan mengatakan bahwa jika $F$ lapangan, $X$ dan $Y$ locally finite poset serta aljabar insidensi $I(X, F)$ dan $I(Y, F)$ isomorfik sebagai aljabar, maka $X$ dan $Y$ isomorfik sebagai poset. Selanjutnya Voss, (1980), membuktikan bahwa isomorfisma pada aljabar insidensi memberikan hasil positif jika ring nya bersifat indecomposable modulo radikal. 
Ribenboim, (1982), membahas isomorfisma untuk kasus ring yang bersifat Notherian. Selain itu Froelich (1985), membuktikan isomorfisma berlaku jika $X$ dan $Y$ merupakan poset berhingga atau $R$ merupakan produk dari ring-ring yang indecomposable. Sedangkan Parmenter et al., (1990), bekerja pada poset $X$ dan $Y$ yang bersifat locally finite yang countable, jika $I(X, F)$ dan $I(Y, F)$ isomorfik sebagai aljabar, maka $X$ isomorfik dengan $Y$. Semua penelitian yang sudah dilakukan itu mensyaratkan bahwa posetnya harus bersifat locally finite. Setelah penelitian aljabar insidensi cukup lama terhenti, maka Spiegel dan Donnell, (1997), mengumpulkan kembali sifat-sifat aljabar insidensi suatu poset atas ring komutatif dengan tetap menggunakan poset locally finite namun memperluas lapangan menjadi ring komutatif.

Dillihat dari tahun penemuannya teori tersebut tampak kuno, namun tetap abadi. Artinya, walaupun topik isomorfisma merupakan masalah lama namun dengan pengembangan pada beberapa hipotesa akan tetap menghasilkan sesuatu yang baru.

Perkembangan aljabar insidensi dalam tahuntahun terakhir beralih pada topik lain, seperti yang dilakukan Thukair et al., (2004), yang menyelidiki sifatsifat aljabar insidensi yang diperlemah dengan mengganti poset dengan proset (preordered set) dengan menghilangkan salah satu sifat pada posetatas ring komutatif yang indecomposible. Di sini prosetnya tidak harus locally finite namun memiliki sifat setiap kelas ekivalen dari elemen-elemen yang ekivalen adalah berhingga. Sementara Spiegel, (2005), membahas tentang kapan suatu aljabar insidensi memiliki anti automorfisma, yang diperlukan untuk menentukan syarat cukup agar sebuah aljabar insidensi memiliki involusi. Selanjutnya Zapatrin, (2008), membahas aljabar insidensi suatu poset yang dibatasi pada sub kategori tidak full dari posetnya, yaitu bekerja pada simplicial complex. Kemudian dengan menggunakan teori kategori dan fungtor dibuktikan bahwa terdapat fungtor dari kategori simplicial complex ke kategori aljabar insidensi, hal ini dipakai untuk masalah yang terkait dengan topologi.

Berdasarkan penjelasan di atas dan mengingat masalah isomorfisma bersifat abadi, dan penemuan yang baru tentang aljabar insidensi finitary serta ide dari aljabar insidensi dengan diperlemah yang mempertahankan sifat keterhinggaan, maka masih dimungkinkan untuk membahas masalah isomorfisma aljabar insidensi atas ring komutatif dengan satuan yang bekerja pada sembarang poset (tidak harus locally finite). Namun ternyata untuk dapat menuju ke sana, diperlukan teorema yang terkait dengan sifat peta unsur - unsur idempoten terhadap suatu morfisma surjektif pada aljabar insidensi finitary yang akan dipakai dalam pembuktian teorema isomorfisma khususnya pada topik isomorfisma potensial.

Namun ternyata teorema inipun dalam pembuktiannya memerlukan teorema lain. Sehingga tulisan ini bertujuan memperoleh teorema dasar yang akan dipakai dalam pembuktian teorema yang lebih besar, yang pada akhirnya akan terpakai dalam masalah isomorfisma pada aljabar insidensi finitary. Sehingga dalam tulisan ini hanya akan dibahas kongruensi dua unsur yang bersifat idempoten ortogonal di aljabar insidensi finitary poset $X$ atas ring $R$ relatif terhadap modulo Jacobson Radikal dari aljabarnya.

\section{BAHAN DAN METODE}

Bahan utama yang dipakai dalam tulisan ini meliputi:

1). Definisi aljabar insidensi yang bekerja pada ring komutatif dan poset yang bersifat spesifik, yaitu locally finite poset (speigel \& Donnell, 1997).

2). Definisi aljabar insidensi yang bekerja pada lapangan (lebih khusus dari pada ring komutatif) namun poset yang diberikan bersifat umum (Kripchenko \& Novikov, 2009).

3). Teorema yang terkait dengan isomorfisma aljabar insidensi yang bekerja pada poset yang khusus, yaitu locally finite poset yang diberikan oleh Voss 1980; Ribenboim 1982; Froelich 1985; Parmenter et al., 1990.

Sedangkan metode yang dilakukan dalam penelitian ini pertama kali mempelajari definisi aljabar insidensi versi Speigel dan versi Kripchenko. Setelah itu membuat definisi baru yang merupakan perluasan kedua versi tersebut yang selanjutnya disebut aljabar insidensi finitary. Kemudian mengambil topik khusus yaitu isomorfisma pada aljabar insidensi, lalu mempelajari teorema-teorema yang terkait dengan isomorfisma aljabar insidensi untuk locally finite poset. Setelah itu mengetahui adanya sifat yang diperlukan untuk membuktikan teorema isomorfisma tersebut, yaitu sifat peta unsur - unsur idempoten ortogonal terhadap suatu isomorfisma aljabar insidensi dan ternyata masih diperlukan sifat lain yang mendasar 
terkait dengan eksistensi elemen idempoten di ring yang memenuhi sifat tertentu. Setelah itu, bergerak dari hal yang paling mendasar dalam teorema isomorfisma akan diselidiki sifat yang mendasar tersebut yang terkait dengan eksistensi elemen idempoten di ring yang memenuhi sifat tertentu dengan menggunakan kongruensi dua unsur yang bersifat idempoten ortogonal pada aljabar insidensi finitary poset sembarang atas ring komutatif relatif terhadap modulo Jacobson Radikal dari aljabarnya. Sifat tersebut dinyatakan dalam bentuk teorema yang dalam pembuktiannya menggunakan definisi baru dan memperhatikan aspek-aspek yang harus dipenuhi dalam definisi tersebut, khususnya sifat keterhinggaannya.

\section{HASIL DAN PEMBAHASAN}

Aljabar insidensi yang didefinisikan oleh Spiegel dan Donnell (1997); bekerja atas ring komutatif namun terbatas pada poset yang locally finite. Sedangkan Aljabar insidensi yang didefinisikan oleh Kripchenko dan Novikov (2009), hanya bekerja pada lapangan, yaitu struktur yang lebih sempurna atau lebih khusus dibandingkan dengan ring komutatif, namun demikian dalam definisi ini poset yang diberikan bersifat umum. Dalam tulisan ini, aljabar insidensi yang diberikan merupakan perluasan dari keduanya, yaitu bekerja pada ring komutatif dan menggunakan sembarang poset yang selanjutnya akan disebut aljabar insidensi finitary yang didefinisikan sebagai berikut :

Definisi : Aljabar insidensi finitary dari sembarang poset $X$ atas ring komutatif $R$, didefinisikan sebagai $\operatorname{FININC}(X, R)=\{f: X \times X \rightarrow R: \forall x, y \in X, x \leq y$, terdapat hanya sejumlah hingga pasangan $(x, y)$ dengan $x \leq x_{1} \leq x_{2} \leq y$ dan $\left.f\left(x_{1}, x_{2}\right) \neq 0_{R}\right\}$

Dengan operasi :

$(f+g)(x, y)=f(x, y)+g(x, y)$

$(f . g)(x, y)=\sum_{x \leq z \leq y} f(x, y) \cdot g(x, y)$

$(r . f)(x, y)=r . f(x, y)$, untuk setiap $f, g \in \operatorname{FININC}(X, R)$ dan $x, y, z \in X$.

FININC $(X, R)$ memiliki struktur $R$-aljabar.

Dari definisi baru di atas terlihat bahwa walaupun posetnya diambil sembarang, namun sifat keterhinggaanya tetap dipertahankan dengan cara memberikan syarat tambahan sejumlah hingga sub interval yang berupa pasangan unsur. Hal ini yang akan menjamin agar operasi perkaliannya terdefinisi.
Beberapa notasi dan istilah yang akan dipakai dalam tulisan ini meliputi :

1. $\delta_{x y} \in \operatorname{FININC}(X, R)$ didefinisikan sebagai $\delta_{x y}(u, v)=$

$\{1$, jika $u=x$ dan $v=y$

$\{0$, yang lainnya

2. Untuk $x=y$ pada sifat 1 , maka $\delta_{x x}$ akan dinotasikan dengan $e_{x^{*}}$

3. $J(R)$ melambangkan Jacobson radikal ring komutatif $R$ dengan satuan. $J(R)$ tidak memuat idempoten yang tak trivial, artinya setiap unsur idempoten di $J(R)$ adalah 0.

4. Jika $R$ pada 3 diganti dengan $\operatorname{FININC}(X, R)$, maka akan diperoleh Jacobson radikal dari Aljabar insidensi finitary $\operatorname{FININC}(X, R)$ yang dinotasikan dengan $J(F I N I N C(X, R))$ yaitu himpunan yang memuat semua fungsi-fungsi $f \in \operatorname{FININC}(X, R)$ sedemikian hingga $f(x, x) \in J(R), \forall x \in X$. Dilihat dari syarat keanggotaannya, secara matematis dapat dituliskan sebagai $J(F I N I N C(X, R))=\{f \in F I N I N C(X, R) \mid f(x, x)$ $J(R), \forall x \in X\}$

5. Jika setiap unsur idempoten di $J(F I N I N C(X, R))$ adalah 0 , maka diperoleh $Z(F I N I N C(X, R))=\{f \in$ $\operatorname{FININC}(X, R) \mid f(x, x)=0, \forall x \in X\}$.

Selanjutnya akan dilihat sifat utama yang terkait dengan unsur idempoten dalam aljabar insidensi finitary dalam bentuk teorema. Dalam pembuktiannya harus diperhatikan betul langkahnya, mengingat poset yang dipakai bersifat umum, namun sifat keterhinggannya harus tetap dipertahankan agar sesuai dengan definisi baru yang diberikan sehingga peninjauan beberapa kasus perlu dilakukan.

Teorema : Misalkan $X$ adalah poset, dan $R$ ring komutatif dengan satuan. Anggap bahwa $x \in X$ dan $g$, $h \in F I N I N C(X, R)$ bersifat idempoten orthogonal dengan $e_{x}=g+h(\bmod J(F I N I N C(X, R)))$. Maka terdapat sebuah elemen idempoten $\alpha \in R$ sedemikian hingga $g \alpha . e_{x}(\bmod Z(F I N I N C(X, R)))$ dan $h(1-\alpha) \cdot e_{x}(\bmod$ $Z(F I N I N C(X, R)))$

\section{Bukti :}

Diketahui $g$ dan $h$ idempoten orthogonal di $\operatorname{FININC}(X, R)$, sehingga berlaku $(g . h)(x, x)=\mathrm{S} g(x, x)$ $h(x, x)=g(x, x) h(x, x)=0$.

Hal ini berarti $g(x, x)$ dan $h(x, x)$ idempoten orthogonal di $R$. Lebih lanjut $1-(g(x, x) h(x, x))$ idempoten di $R$, dan merupakan anggota $J(R)$. Hal ini dapat dijelaskan sebagai berikut. 
Perhatikan bahwa

$(1-(g(x, x)+h(x, x)))^{2}$

$=1-(g(x, x)+h(x, x))-(g(x, x)+h(x, x))+(g(x, x)+h(x, x))^{2}$

$=1-g(x, x)-h(x, x)-g(x, x)-h(x, x)+(g(x, x))^{2}+2 g(x, x)$

$h(x, x)+(h(x, x))^{2}$

$=1-g(x, x)-h(x, x)-g(x, x)-h(x, x)+g(x, x)+0+h(x, x)$

$=1-(g(x, x)+h(x, x))$

Jadi $1-(g(x, x)+h(x, x))$ bersifat idempoten. Selanjutnya karena $e_{x} g+h(\bmod J(F I N I N C(X, R)))$ maka $e_{x}-(g+h)$ $\in J(F I N I N C(X, R))$. Akibatnya $\left(e_{x}-(g+h)\right)(x, x) \in J(R)$ yang berimplikasi $e_{x}(x, x)-(g+h)(x, x) \in J(R)$. Jadi $1-$ $(g(x, x)+h(x, x)) \in J(R)$.

Dari uraian di atas dapat disimpulkan bahwa $1-(g(x, x)+h(x, x))$ adalah unsur idempoten yang berada di $J(R)$, sehingga $1-(g(x, x)+h(x, x))=0$ yang berakibat $1=(g(x, x)+h(x, x))$.

Selanjutnya tulis $\alpha \in R$ sebagai $\alpha=g(x, x)$, harus dibuktikan bahwa

1. $g \alpha . e_{x}(\bmod Z(\operatorname{FININC}(X, R)))$ dan

2. $h(1-\alpha) \cdot e_{x}(\bmod Z(F I N I N C(X, R)))$

Untuk membuktikan point 1 ,

Perhatikan bahwa $\left(g-\alpha . e_{x}\right)(y, y)=g(y, y)-\alpha \cdot e_{x}(y, y)$, selanjutnya pandang untuk dua kasus, yaitu untuk $y=x$ dan $y \quad x$

a. Untuk $y=x: g(y, y)-\alpha \cdot e_{x}(y, y)=g(x, x)-\alpha=g(x, x)-$ $g(x, x)=0$

b. Untuk $\boldsymbol{y} \boldsymbol{x}$

Dari hipotesa teorema diketahui bahwa $e_{x}-(g+h) \in$ $J(F I N I N C(X, R))$ sehingga $\left(e_{x}-(g+h)\right)(y, y) \in J(R)$ ekivalen dengan $e_{x}(y, y)-(g(y, y)+h(y, y)) \in J(R)$ yang menghasilkan - $(g(y, y)+h(y, y)) \in J(R)$. Tetapi $g(y, y)+$ $h(y, y)$ idempoten, sehingga $g(y, y)+h(y, y)=0$, hal ini berarti $g(y, y)=-h(y, y)$ yang berimplikasi $g(y, y) g(y, y)=$ - $h(y, y) g(y, y)$ dan akibatnya $g(y, y)=0$ (karena $g$ idempoten and $g, h$ orthogonal). Sehingga ( $g-\alpha$ .$\left.e_{x}\right)(y, y)=g(y, y)-\alpha \cdot e_{x}(y, y)=0$, hal ini berarti $g \alpha . e_{x}$ $(\bmod Z(F I N I N C(X, R)))$.

Selanjutnya akan dibuktikan bahwa $h(1-\alpha) \cdot e_{x}$ $(\bmod Z(F I N I N C(X, R)))$. Perhatikan bahwa $(h-(1-\alpha)$ .$\left.\left.\left.\left.e_{x}\right)(y, y)=h(y, y)\right)-e_{x}(y, y)\right)+\alpha \cdot e_{x}(y, y)=h(y, y)-e_{x}(y, y)\right)+$ $g(y, y) e_{x}(y, y)$

Untuk kesamaan terakhir ini akan dipandang dua kasus sebagai berikut:

a. Untuk $\boldsymbol{y}=\boldsymbol{x}$ dan dengan menggunakan (1), diperoleh: $\left.\left.h(y, y)-e_{x}(y, y)\right)+g(y, y) e_{x}(y, y)=h(x, x)-e_{x}(x, x)\right)+g(x, x)$ $e_{x}(x, x)=h(x, x)-1+g(x, x)=h(x, x)+g(x, x)-1=0$

\section{b.Untuk $y x$}

$\left.h(y, y)-e_{x}(y, y)\right)+g(y, y) e_{x}(y, y)=h(y, y)$. Selanjutnya klaim bahwa $h(y, y)=0$.

Pembuktian klaim serupa dengan kasus untuk $g(y, y)$ sebagai berikut.

Karena $e_{x}-(g+h) \in J(F I N I N C(X, R))$ maka jika dikenakan pada $(y, y) \hat{I} X \times X$ didapat $e_{x}-(g+h)(y, y) \in$ $J(R)$ yang berimplikasi $e_{x}(y, y)-(g(y, y)+h(y, y)) \in J(R)$ dan akibatnya

$-(g(y, y)+h(y, y)) \in J(R)$. Tetapi $g(y, y)+h(y, y)$ idempoten, dan karena setiap unsur idempoten di $J(R)$ adalah 0 , maka $g(y, y)+h(y, y))=0$, akibatnya $h(y, y)=-g(y, y)$ yang berimplikasi $h(y, y) h(y, y)=-g(y, y) h(y, y)$ dan akibatnya $h(y, y)=0$, (karena $h$ idempoten dan $g, h$ orthogonal). Sehingga $h(y, y)-e_{x}(y, y)+g(y, y) e_{x}(y, y)=0$. Hal ini berarti $h(1-\alpha) \cdot e_{x}(\bmod Z(F I N I N C(X, R)))$.

\section{KESIMPULAN}

Hal penting yang dapat disimpulkan dalam tulisan ini adalah adanya definisi baru tentang aljabar insidensi finitary yang merupakan perluasan dari definisi sebelumnya. Munculnya teorema yang terkait dengan unsur idempoten dalam aljabar insidensi finitary yang dalam pembuktiannya menggunakan definisi baru tersebut, sehingga harus memperhatikan hal-hal yang disyaratkan pada definisi yang diberikan, yaitu khususnya pada syarat keterhinggaannya. Teorema ini merupakan teorema dasar yang akan dipakai dalam pembuktian teorema lain yang terkait dengan sifat peta unsur - unsur idempoten terhadap suatu morfisma surjektif pada aljabar insidensi finitary. Teoremateorema tersebut pada akhirnya akan berguna untuk mengkaji masalah isomorfisma dalam Aljabar insidensi finitary.

\section{UCAPAN TERIMAKASIH}

Ucapan terima kasih disampaikan kepada Dr.Zhao Dongsheng, staff di MME,NIE, National Technological University, Singapore yang telah memberikan masukan dalam penulisan paper ini selama penulis mengikuti program sandwich 2009 di Singapore, yang didanai Dikti dengan Nomor Kontrak 2042/D4.4/2009 Tgl 07 Agustus 2009.

\section{DAFTAR PUSTAKA}

Froelich, J. 1985. The isomorphism problem for incidence ring. Illionis Journal Math 29:146-152. 
Khripchenko, N. S. \& Novikov, B.V. 2009. Finitary incidence algebras, Communications in Algebra 37: 1670-1676.

Parmenter, M.M., Schmerl, J. \& Spiegel, E. 1990. Isomorphic incidence algebras. Advances in Mathematics 84:226-236.

Ribenboim, P. 1982. The algebra of functions of a graph. Studia Sci. Math. Hungar 17:1-20.

Spiegel, E. \& O'Donnell, C. 1997. Incidences Algebra. New York: Marcel Dekker, Inc.

Spiegel, E. 2005. Involutions in Incidences Algebras. Journal Linear Algebra and its Applications 405: 155-162.
Stanley, R.P. 1970. Structure of incidence algebras and their automorphism Groups. Bull. AMS 76: 1236-1239.

Voss, E.R. 1980. On the isomorphism problem for incidence ring. Illionis Journal Math 24: 24-638.

Thukair, Fawzi. \& Singh Surjeet. 2004. Weak Incidence Algebra and Maximal Ring of Quotients. Journal IJMMS 53: 28352845.

Zapatrin, R. 2008. Incidence Algebra of Simplicial Compexes. http://arxiv.org/PS cache/math/pdf/0001/0001065v1.pdf (1 September 2010). 